\title{
Biotrophy and rust haustoria
}

\author{
KURT MENDGEN*, GHRISTINE STRUCK, RALF T. VOEGELE and MATTHIAS HAHN \\ Universität Konstanz, Department of Biology, Phytopathology, D-78457 Konstanz, Germany
}

(Accepted for publication March 2000)

\section{INTRODUCTION}

Haustoria produced by biotrophic fungi and Oomycetes are extensions into living host cells. However, they are not truly intracellular. They breach the cell wall only and a newly formed host plasma membrane (the extrahaustorial membrane) surrounds them, resulting in a close association of fungal and plant membranes only separated by a thin fungal wall and an extrahaustorial matrix. The extrahaustorial matrix is mainly of host origin. Heath and Skalamera [23] suggest that this interface is the site for translocation of nutrients and exchange of information. Two more aspects seem to be of utmost importance. First, the fungal haustorium must not be recognized as foreign by the host in order to avoid defence reactions. Second, the fungus should modify the host's metabolite flow to ensure optimal access to these resources.

\section{THE HAUSTORIUM, A SPECIALIZED HYPHAL BRANCH}

The fungal haustorium may be a short or long simple unbranched projection from an intercellular hypha. It may be an extensively lobed or branched structure, or it may be differentiated as a neck with a haustorial body attached, each with specialized wall structures [9]. The morphological spectrum is exemplified best by the rust fungi which have monokaryotic and dikaryotic stages with very different morphologies of haustoria. The monokaryon produces M-haustoria. Compared to hyphae, they exhibit only a few structural modifications during growth into host cells [13], yet, the extrahaustorial membrane surrounding the M-haustorium is modified compared with the plant plasma membrane [1]. In contrast, the dikaryon differentiates the haustorial mother cell in close contact with the plant cell wall, and the haustorium consists of a tubular neck connected

\footnotetext{
* To whom all correspondence should be addressed. E-mail:
} Kurt.W.Mendgen@uni-konstanz.de to a haustorial body reaching into the host cell. Around the neck is an iron- and phosphorus-rich neckband which bridges the plant and fungal plasma membrane. It seems to serve as a seal against the flow of solutes from the extrahaustorial matrix into the apoplast of the plant [17, $20,22]$. The lack of intramembrane particles, as revealed by freeze fracture electron microscopy and different cytochemical methods, convincingly demonstrated that the extrahaustorial membrane differs from "conventional membranes" in plant cells [17]. Although these methods were unable to reveal the molecular basis of such modifications, they proved the existence of a specialized membrane surrounding the haustorium. In light of the apparent similar tasks that these diverse morphological types of haustoria perform, the question arises whether they share common molecular properties.

\section{PROBABLE HAUSTORIAL FUNCTIONS}

Haustoria appear to have two main tasks: (1) the regulation of the host-parasite interaction, and (2) the uptake of nutrients.

Numerous experiments have characterized the host range of rust fungi which is usually restricted to related host species [10]. A comparison of haustoria from closely related rusts revealed unique structural modifications for each species [3, 4]. Also, the same host plant shows species-specific interactions with different rusts: Oat plants infected with Puccinia graminis, develop endoplasmatic reticulum derived membranes with small interconnected tubules, whereas after infection with $P$. coronata, they form very different long and narrow tubular extensions [17]. These observations suggest that, apart from the signals exchanged between host and parasite during development of infection structures [21], formation of the fine structure of the haustorial parasitehost interface occurs under the control of species- or even race-specific signals. Such signals may include suppressors. Suppressors have been postulated to be involved in 
maintaining basic compatibility between biotrophic fungi and their host plants [6]. Evidence for suppressors comes from a phenomenon called induced susceptibility. French bean tissue already infected by Uromyces vignae supported additional infections by several nonhost pathogens [8]. Similarly, haustoria of Erysiphe graminis, the powdery mildew pathogen, can induce such susceptibility [29]. However, experimental evidence for suppressors from these fungi is still weak $[2,34]$.

Evidence for the uptake of defined host metabolites, such as sugars and amino acids, by rust haustoria is scarce and mostly indirect. Studies with radioisotopes started more than three decades ago [25]. They have the disadvantage that any labelled substrate fed to infected host plants is metabolized to a certain extent on its path to the fungus. In addition, depending on the isotope used, ${ }^{14} \mathrm{CO}_{2}$ or ${ }^{3} \mathrm{H}_{2} \mathrm{O}$ may develop as products and obscure the results. Efforts to differentiate between uptake by haustoria or by intercellular hyphae revealed some trends, but were not able to trace the fate of single compounds from the plant cell into the haustorium [33]. In powdery mildews, the role of haustoria in nutrient uptake is more evident, because they are the only fungal structures within the host tissue. Feeding experiments with radiolabelled sugars seemed to indicate that glucose, and not sucrose, is the main carbohydrate obtained from epidermal cells [46].

On the basis of inhibitor studies with haustoria of E. graminis, Gay et al. [11] and Manners [32] suggested that the extrahaustorial membrane loses control of solute export and that ATPase activity of the haustorial plasma membrane would support a high flux of solutes across the haustorial interface. However, the lead precipitation technique used to detect meaningful membrane ATPase activity on the host or the fungal side has given inconsistent results $[1,48]$. This technique has been debated since its development [27, 39, 42], and immunocytological data are urgently needed to clarify the localization of the plasma membrane ATPase.

\section{ENZYMES INVOLVED IN SUBSTRATE UPTAKE BY FUNGAL HYPHAE}

Wild Saccharomyces cerevisiae has become one of the model organisms for the characterization of structure and function of plasma membrane transport proteins $[38,40]$, surprisingly little is known about the molecular aspects of transport processes across the cytoplasmic membrane of filamentous fungi. In Neurospora crassa, one of the best studied species, facilitators and secondary transporters have been found with specificities for amino acids, hexoses and ions $[5,26]$. Studies with symbionts, such as mycorrhizal fungi or obligately biotrophic parasites, have been hampered by the close association of fungus and plant. Nehls and coworkers [36, 37] have cloned the first plasma membrane transporters for sugars and amino acids from the ectomycorrhizal fungus Amanita muscaria. The authors demonstrated regulation of the corresponding genes in response to different metabolites in mycelium grown in vitro and performed a biochemical characterization of the transporters expressed in yeast. However, the roles of these transporters in fungal nutrition and symbiosis remain speculative since no data regarding the localization and distribution of these transporters in planta are available. Harrison and van Buuren [19] have cloned a phosphate transporter from the VA-mycorrhizal fungus Glomus versiforme by expression in yeast. By means of RT-PCR, they localized transcripts of the transporter in external hyphae of symbiotically growing $G$. versiforme. These data provided the first piece of molecular evidence for the postulated nutrient fluxes in VA-mycorrhizae.

\section{TRANSPORT PROTEINS IN HAUSTORIA}

Based on the screening of a rust haustorium-specific cDNA-library, genes encoding three amino acid transporters (AAT1, AAT2, AAT3) were isolated. AAT2 (formerly PIG2) and AAT3 are amino acid transporters based on sequence homology [15, 16, M. Hahn, unpublished]. AAT1 (formerly PIG27) was expressed in amino acid uptake deficient yeast cells, enabling the transformants to take up histidine and lysine (M. Hahn, unpublished). Antibodies raised against synthetic peptides from the predicted sequence of AAT2p demonstrated that the putative amino acid transporter is localized to the plasma membrane of the haustorial body. In addition, a hexose transporter gene (HXT1) was isolated (R. Voegele, unpublished). Preliminary results with antibodies raised against portions of HXTlp indicate that this protein has a similar localization as AAT2p. In agreement with homologous transporters from other organisms, heterologous expression and characterization in yeast mutants or Xenopus oocytes classified the transporters found so far in $U$. fabae as $\mathrm{H}^{+}$/solute symporters (C. Struck, unpublished).

Plasma membrane $\mathrm{H}^{+}$-ATPase plays a key role in active nutrient uptake. The first biochemical evidence for the existence of this enzyme was obtained using microsomal vesicles of isolated haustoria of $U$. fabae. Compared with ungerminated urediospores and germ tubes, the hydrolytic activity of the haustorial $\mathrm{H}^{+}$ATPase is several-fold higher, suggesting that the enzyme plays an important role in rust haustoria [44]. Molecular analysis revealed a single copy gene, PMA1, encoding the $U$. fabae plasma membrane $\mathrm{H}^{+}$-ATPase. Little changes in transcript levels were detected, suggesting that regulation 
of PMA1 expression occurs on a post-transcriptional level. Functional expression of PMAlp in yeast opened the possibility to explore enzymatic activity and regulation in detail. The results demonstrated that 76 amino acids of the C-terminus are not essential for enzyme activity [45]. This is similar to the $\mathrm{H}^{+}$-ATPases of yeast and plants, where the removal of the C-termini activates substrate hydrolysis, suggesting that they constitute autoregulatory domains [41]. Nevertheless, the regulatory mechanisms of the rust fungus plasma membrane ATPase in their entirety remain unclear.

\section{GENES EXPRESSED IN HAUSTORIA}

Given the apparent importance of haustoria not only in nutrient uptake, but also in the regulation of the hostparasite interaction, efforts to isolate haustorium-specific proteins or genes were undertaken with several hostparasite systems. The first steps were based on isolating haustoria from infected leaf tissue, either by differential centrifugation $[12,47]$ or by affinity chromatography with the lectin concanavalin A [14]. Two different experimental strategies were followed. One used the generation of monoclonal antibodies for the identification of haustorium-specific epitopes. By this means, haustorium-specific plasma membrane glycoproteins from pea powdery mildew were identified $[30,31]$, and three carbohydrate epitopes restricted to the haustorial cell wall of flax rust $[18,35]$. While this strategy has revealed for the first time molecular differentiation of haustoria, it has proven difficult to identify the genes corresponding to the epitopes.

The other strategy is aimed at gene expression, with the following rationale. By isolating phase-specifically expressed genes and analysing their function, one can "watch" molecular events and predict metabolic activities within the biotrophic rust mycelium without interference from similar activities within the plant cell. From isolated haustoria of $U$. fabae, mRNA was prepared and used for the construction of a library that contained almost exclusively haustorial cDNAs. Differential screening of this library revealed a large number (about 20\%) of in planta-induced genes $(P I G \mathrm{~s})$ some of which are very highly expressed in haustoria but not or only at low levels in germinated spores and early infection stages [15]. This distinct expression pattern indicated that haustoria are specialized cells performing unique functions.

As estimated from the frequency of cDNAs in the library, about $3 \%$ of the haustorial mRNA encode the amino acid and hexose transporters mentioned above. In addition, two of the most highly expressed genes, which together represent about $5 \%$ of the haustorial mRNA, were found to encode homologs of genes involved in vitamin B1 synthesis [15] which acts as a cofactor of several key enzymes in primary carbohydrate and amino acid metabolism [24]. The identities of THI1 (formerly PIG1) and THI2 (formerly PIG4) were confirmed by complementation of genetically defined thiamine auxotrophic mutants of Schizosaccharomyces pombe. Immunocytochemistry revealed a very high concentration of THIlp in haustoria, but much lower amounts in intercellular hyphae and sporulating tissue [43].

Our data indicate that haustoria play a major role not only in nutrient uptake but also in biosynthetic activities. This is supported by random EST sequencing of haustorial cDNAs, revealing the activity of several genes possibly involved in amino acid biosynthesis (M. Hahn, unpublished).

\section{CURRENT HYPOTHESIS OF RUST HAUSTORIAL SUBSTRATE UPTAKE}

There has been a long dispute about the main sites of nutrient uptake by rust fungi. Since the flow of host carbohydrates is redirected to the site of infection, and intercellular hyphae represent the major part of the parasitic mycelium, it has been suggested that the mycelium might be sufficient to serve that role [28]. Early observations showing an increased efflux of amino acids and sugars from cells of the leaf parenchyma during later stages of rust infection, seemed to support this assumption [7]. In contrast, cytological studies suggested a central role for haustoria in the parasitic life of fungi. Electron microscopy revealed that, compared to the vacuolated protoplasts of intercellular hyphae, the cytoplasm of haustoria is dense and accumulates in the haustorial body. Mitochondria tend to be lined along the haustorial plasmalemma [17]. Our current molecular and cytological data also support the central role of haustoria in amino acid uptake, including related metabolic activities. In spite of major morphological differences, mono- and dikaryotic haustoria display similar molecular properties as demonstrated by the localization of AAT2p. The putative amino acid transporter is detected only in the distal part of the monokaryotic haustorium [Fig. 1(a)] and in the dikaryotic haustorial body distal to the haustorial neck [Fig. 1(b)]. Molecular differentiation of the fungal membrane does not occur at the border defined by the neck band, but between domains of the membrane that are morphologically not distinct. Especially in Mhaustoria, expression of AAT2p seems to occur only late after penetration of the host cell, with minimal subsequent lateral diffusion of the transport protein. However, haustoria not only concentrate on amino acid uptake and utilization. Our current work indicates an additional major role in sugar metabolism. We are now characterizing a putative invertase (INV1p) possibly secreted into the extrahaustorial matrix, a hexose transporter (HXTlp) in the plasma membrane of the haustorial 

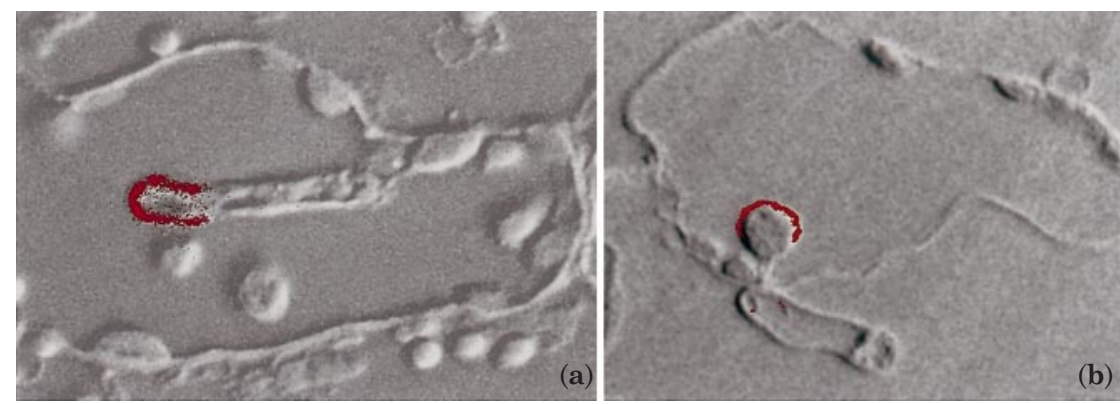

FIG. 1. Localization of the putative amino acid transporter AAT2p (secondary antibody: Cy3 anti-rabbit IgG) in haustoria of (a) the monokaryon and (b) the dikaryon of Uromyces fabae. Fluorescence is superimposed on the images obtained with differential interference contrast microscopy $(\times 2000)$.

body and a mannitol dehydrogenase (MADlp), probably involved in the conversion of hexoses and hexitols (R. Voegele and M. Hahn, unpublished). Estimations of the transcript levels in haustoria indicate a major role of these genes in channeling sugars across the extrahaustorial matrix. Thus, our data of differential gene activity in haustoria suggest that the rust haustorium is one, if not the main source and distributor of amino acids and carbohydrates (probably mannitol) for the rust fungus. However, these results introduce us to only some of the basic task of haustoria. Other major properties, such as the suppression of plant defence reactions or the induction of an extrahaustorial membrane with special characteristics, are still far from being understood.

We thank Heinz Vahlenkamp for expert microscopy, the Deutsche Forschungsgemeinschaft and the Fonds der Chemischen Industrie for financial support and Roland Rohringer and Don Harder for reading the manuscript.

\section{REFERENCES}

1. Baka ZA, Larous L, Lösel DM. 1995. Distribution of ATPase activity at the host-pathogen interfaces of rust infections. Physiological and Molecular Plant Pathology 47: 67-82.

2. Beissmann B, Kogel KH. 1991. Identification and characterization of suppressors. In: Linsken HF, Jackson JF, eds. Plant Toxin Analysis. Berlin: Springer, 259-275.

3. Berndt R. 1999. Neotropical rust fungi: New species and observations. Mycologia 91: 1045-1059.

4. Berndt R, Oberwinkler F. 1997. Haustorial ultrastructure and morphology of Melampsorella and Thekopsora areolata. Mycologia 89: 698-705.

5. Burgstaller W. 1997. Transport of small ions and molecules through the plasma membrane of filamentous fungi. Critical Reviews in Microbiology 23: 1-46.

6. Bushnell WR, Rowell JB. 1981. Suppressors of defence reactions: A model for roles in specificity. Phytopathology 71: 1012-1014.

7. Elnaghy M, Heitefuss R. 1976. Permeability changes and production of antifungal compounds in Phaseolus vulgaris infected with Uromyces phaseoli. I. The role of the spore germination self-inhibitor. Physiological Plant Pathology 8: 253-267.

8. Fernandez MR, Heath MG. 1991. Interactions of the nonhost French bean plant (Phaseolus vulgaris) with parasitic and saprophytic fungi. IV. Effect of preinoculation with the bean rust fungus on growth of parasitic fungi nonpathogenic on beans. Canadian Fournal of Botany 69: 1642-1646.

9. Fink S. 1999. Pathological and Regenerative Plant Anatomy. Berlin, Stuttgart: Borntraeger.

10. Gäumann E. 1959. Die Rostpilze Mitteleuropas. Bern: Bücheler.

11. Gay JL, Salzberg A, Woods AM. 1987. Dynamic experimental evidence for the plasma membrane ATPase domain hypothesis of haustorial transport and for ionic coupling of the haustorium of Erysiphe graminis to the host cell (Hordeum vulgare). The New Phytologist 107: 541-548.

12. Gil F, Gay JL. 1977. Ultrastructural and physiological properties of the host interfacial components of haustoria of Erysiphe pisi in vivo and in vitro. Physiological Plant Pathology 10: 1-10.

13. Gold RE, Mendgen K. 1991. Rust basidiospore germlings and disease initiation. In: Cole GT, Hoch HC, eds. The Fungal Spore and Disease Initiation in Plants and Animals. New York: Plenum Publishing Corp, 67-99.

14. Hahn M, Mendgen K. 1992. Isolation by Con A binding of haustoria from different rust fungi and comparison of their surface qualities. Protoplasma 170: 95-103.

15. Hahn M, Mendgen K. 1997. Characterisation of in planta induced rust genes isolated from a haustorium-specific cDNA library. Molecular Plant Microbe Interactions 10: 427-437.

16. Hahn M, Neef U, Struck C, Göttfert M, Mendgen K. 1997. A putative amino acid transporter is specifically expressed in haustoria of the rust fungus Uromyces fabae. Molecular Plant-Microbe Interactions 10: 438-445.

17. Harder DE, Ghong J. 1991. Rust haustoria. In: Mendgen K, Lesemann D-E, eds. Electron Microscopy of Plant Pathogens. Berlin: Springer, 235-250.

18. Hardham AR, Mitchell HJ. 1998. Use of molecular cytology to study the structure and biology of phytopathogenic and mycorrhizal fungi. Fungal Genetics and Biology 24: 252-284.

19. Harrison MJ, van Buuren ML. 1995. A phosphate transporter from the mycorrhizal fungus Glomus versiforme. Nature 378: 626-629.

20. Heath MC. 1976. Ultrastructural and functional similarity of the haustorial neckband of rust fungi and the Casparian 
strip of vascular plants. Canadian Fournal of Botany 54: 2484-2489.

21. Heath MC. 1997. Signalling between pathogenic rust fungi and resistant or susceptible host plants. Annals of Botany 80: 713-720.

22. Heath MC, Allen FHE. 1985. Morphology, element composition, and response to acids and oxidizing agents, of the haustorial neckband of Uromyces phaseoli var. vignae. Canadian Fournal of Botany 63: 463-473.

23. Heath MC, Skalamera D. 1997. Cellular interactions between plants and biotrophic fungal parasites. Advances in Botanical Research 24: 195-225.

24. Hohmann S, Meacock PA. 1998. Thiamin metabolism and thiamin diphosphate-dependent enzymes in the yeast Saccharomyces cerevisiae: genetic regulation. Biochimica Biophysica Acta 1385: 201-219.

25. Jäger K, Reisener H-J. 1969. Untersuchungen über Stoffwechselbeziehungen zwischen Parasit und Wirt am Beispiel von Puccinia graminis var tritici auf Weizen. Planta (Berl.) 85: 57-72.

26. Jennings DH. 1995. The Physiology of Fungal Nutrition. Cambridge: Cambridge University Press.

27. Katz D, Sussman M, Mierzwa R, Evert R. 1988. Cytochemical localization of ATPase activity in oat roots localizes a plasma membrane-associated soluble phosphatase, not the proton pump. Plant Physiology 86: 841-847.

28. Kneale J, Farrar JF. 1985. The localization and frequency of haustoria in colonies of brown rust on barley leaves. The New Phytologist 101: 495-505.

29. Lyngkjaer MF, Garver TLW. 1999. Induced accessibility and inaccessibility to Blumeria graminis f. sp. hordei in barley epidermal cells attacked by a compatible isolate. Physiological and Molecular Plant Pathology 55: 151-162.

30. Mackie AJ, Roberts AM, Callow JA, Green JR. 1991. Molecular differentiation in pea powdery-mildew haustoria. Planta 183: 399-408.

31. Mackie AJ, Roberts AM, Green JR, Gallow JA. 1993. Glycoproteins recognised by monoclonal antibodies UB7, UB8 and UB10 are expressed early in the development of pea powdery mildrew haustoria. Physiological and Molecular Plant Pathology 43: 135-146.

32. Manners J. 1989. The host-haustorium interface in powdery mildews. Australian Fournal of Plant Physiology 16: $45-52$

33. Mendgen K. 1981. Nutrient uptake in rust fungi. Phytopathology 71: 983-989.

34. Moerschbacher BM, Schrenk K, Graessner B, Noll U, Reisener HJ. 1990. A wheat cell wall fragment suppresses elicitor-induced resistance responses and disturbs fungal development. Fournal of Plant Physiology 136: 761-764.

35. Murdich LJ, Kobayashi I, Hardham AR. 1998. Production and characterisation of monoclonal antibodies to cell wall components of the flax rust fungus. European Fournal of Plant Pathology 104: 331-346.

36. Nehls U, Kleber R, Wiese J, Hampp R. 1999. Isolation and characterization of a general amino-acid permease from the ectomycorrhizal fungus Amanita muscaria. New Phytologist 144: 343-349.

37. Nehls U, Wiese J, Guttenberger M, Hampp R. 1998. Carbon allocation in ectomycorrhizas: Identification and expression analysis of an Amanita muscaria monosaccharide transporter. Molecular Plant Microbe Interactions 11: 167-176.

38. Nelissen B, DeWachter R, Gofeau A. 1997. Classification of all putative permeases and other membrane plurispanners of the major facilitator superfamily encoded by the complete genome of Saccharomyces cerevisiae. FEMS Microbiological Reviewes 21: 113-134.

39. Novikoff AB. 1970. Their phosphatase controversy: Love's labours lost. Fournal of Histochemistry and Cytochemistry 18: 916-917.

40. Özcan S, Johnston M. 1999. Function and regulation of yeast hexose transporters. Microbiology and Molecular Biology Reviews 63: 554-569.

41. Palmgren MG, Larsson G, Sommarin M. 1990. Proteolytic activation of the plant plasma membrane $\mathrm{H}^{+}$ATPase by removal of a terminal segment. Fournal of Biological Chemistry 265: 13423-13426.

42. Rosenthal A, Moses H, Ganote G. 1970. Interpretation of phosphate cytochemical data. Fournal of Histochemistry and Cytochemistry 18: 915.

43. Sohn J, Voegele RT, Mendgen K, Hahn M. 2000. High level activation of vitamin $\mathrm{Bl}$ biosynthesis genes in haustoria of the rust fungus Uromyces fabae. Molecular Plant Microbe Interactions (in press).

44. Struck C, Hahn M, Mendgen K. 1996. Plasma membrane $\mathrm{H}^{+}$-ATPase activity in spores, germ tubes, and haustoria of the rust fungus Uromyces viciae-fabae. Fungal Genetics and Biology 20: 30-35.

45. Struck C, Siebels G, Rommel O, Wernitz M, Hahn M. 1998. The plasma membrane $\mathrm{H}^{+}$-ATPase from the biotrophic fungus Uromyces fabae: Molecular characterisation of the gene (PMA-1) and functional expression of the enzyme in yeast. Molecular Plant-Microbe Interactions 11: 458-465.

46. Sutton PN, Henry MJ, Hall JL. 1999. Glucose, and not sucrose, is transported from wheat to wheat powdery mildew. Planta 208: 426-430.

47. Tiburzy R, Martins EMF, Reisener HJ. 1992. Isolation of haustoria of Puccinia graminis f. sp. tritici from wheat leaves. Experimental Mycology 16: 324-328.

48. Woods AM, Gay IL. 1988. The interface between haustoria of Puccinia poarum (monokaryon) and Tussilago farfara. Physiological and Molecular Plant Pathology 33: 296-301. 